\title{
Indeks Keberlanjutan Dimensi Peraturan Dalam Perencanaan Pembangunan PLTN Di Indonesia
}

\author{
Maya Dewi Dyah Maharani *1, June Mellawati \\ ${ }^{1}$ Universitas Sahid Jakarta, Jurusan Teknik Lingkungan, Jl. Prof. Dr. Supomo, SH No. 84 Tebet, Jakarta Selatan 12870 \\ 2BATAN,Pusat Teknologi Keselamatan dan Metrologi Radiasi, Jl. Lebak Bulus Raya 49, Ps. Jumat PO Box 7043, Jaksel 12070
}

\begin{tabular}{l}
\hline INFORMASI ARTIKEL \\
\hline Riwayat Artikel: \\
Diterima: \\
02 April 2019 \\
Diterima dalam bentuk revisi: \\
12 April 2019 \\
Disetujui: \\
09 Mei 2019 \\
\end{tabular}

Kata kunci:

keberlanjutan,

PLTN,

multi dimensional scaling

(MDS)

\begin{abstract}
ABSTRAK
INDEKS KEBERLANJUTAN DIMENSI PERATURAN DALAM PERENCANAAN PEMBANGUNAN PLTN DI INDONESIA. Salah satu manfaat nilai indeks keberlanjutan dimensi peraturan untuk menyempurnakan peraturan perencanaan pembangunan PLTN sampai di tingkat pemerintah daerah, serta sebagai bahan masukan dokumen Rencana Pembangunan Jangka Panjang (RPJP) di Indonesia. Tujuan kajian mendapatkan nilai indeks keberlanjutan dari dimensi peraturan dalam rangka rencana pembangunan pembangkit listrik tenaga nuklir (PLTN) di Indonesia seiring revolusi industri 4.0. Metode kajian menggunakan analisis Multi Dimensional Scaling (MDS) dengan memetakan persepsi (perceptual mapping) yang mengandalkan Euclidian Distance antara satu atribut dengan atribut lainnya. Hasil analisis MDS yang menyertakan 16 peraturan menunjukan indeks keberlanjutan dimensi peraturan sebesar 42,89 (belum berkelanjutan). Sebagai langkah nyata, Peraturan Pemerintah RI No.61 tahun 2013 tentang Pengelolaan Limbah Radioaktif dengan RMS 6,43, dan Keputusan Presiden No. 106 tahun 2001 tentang Pengesahan Konvensi Keselamatan Nuklir dengan RMS 6,18 layak disertakan dalam dokumen perencanaan untuk level provinsi dan daerah.
\end{abstract}

\begin{abstract}
SUSTAINABILITY INDEX OF REGULATION DIMENSIONS IN NUCLEAR POWER PLANT (NPP) DEVELOPMENT PLANNING IN INDONESIA. One of the benefits of regulatory dimensions of sustainability index value to improve the regulation of The Nuclear Power Plant development planning at the level of local government, as well as inputing of Long Term Development Plan Documents (RPJP) in Indonesia. The purpose of the study was to obtain a sustainability index value from the regulatory dimension in the framework of the plan to build NPP in Indonesia along with the industrial revolution 4.0. The study method uses Multi Dimensional Scaling (MDS) analysis by mapping perceptual mapping that relies on Euclidian Distance between one dimensions to the other dimensions. The results of the MDS analysis which included 16 regulations showed a sustainability index of the regulatory dimension of 42.89 (not yet sustainable). As a concrete step, RI Government Regulation No.61 of 2013 concerning Management of Radioactive Waste with RMS 6.43, and Presidential Decree No. 106 of 2001 concerning Ratification of the Nuclear Safety Confession with RMS 6.18 eligible to be included in planning documents for provincial and regional levels.

Keywords: sustainability, NPP, Multi Dimensional Scaling (MDS)
\end{abstract}

(C) 2019 Jurnal Pengembangan Energi Nuklir. All rights reserved

\section{PENDAHULUAN}

Dimensi peraturan perundang-undangan ketenaganukliran merupakan seperangkat peraturan yang mengatur, mengarahkan dan melindungi pemanfaatan ketenaganukliran, yang pelaksanaannya dalam bentuk undang-undang, peraturan pemerintah, peraturan presiden, peraturan badan pengawas dan peraturan pelaksana lainnya. Ketenaganukliran merupakan

*Penulis korespondensi.

E-mail: mayasudarsono@gmail.com pemanfaatan, pengembangan, serta penguasaan ilmu pengetahuan dan teknologi nuklir dan pengawasan segala kegiatan terkait dengan tenaga nuklir. Tenaga nuklir adalah tenaga dalam bentuk apapun yang dibebaskan dalam proses transformasi inti, termasuk tenaga yang berasal dari sumber radiasi pengion [1].

Era Revolusi Industri 4.0 berfokus pada kemajuan teknologi masa kini, dan terkait teknologi nuklir dalam menyambut Revolusi Industri 4.0 tersebut telah dilakukan kerjasama antara 
Menristekdikti dengan Dirjen IAEA yang bertujuan memperkuat komitmen kerjasama dalam pengembangan, serta pemanfaatan teknologi nuklir untuk damai. Sesuai mandat IAEA, adanya kerjasama ini akan menguntungkan posisi Indonesia dalam upaya memperluas kontribusi energi nuklir dengan negara berkembang lainnya untuk perdamaian, kesehatan dan kesejahteraan di seluruh dunia [2].

Seperti diketahui, revolusi industri 1.0 dimulai ketika ditemukannya mesin uap pada tahun 1780an, dan hal ini berkembang hingga pertengahan abad 21 berbasis industri mekanik, berdaya air dan uap. Akhir abad 19, revolusi industri 2.0 ditandai dengan kemampuan produksi secara massal dengan tenaga listrik berbasis pembagian kerja (assembly line), lalu tahun 1970an dimulai era revolusi industri 3.0 dengan otomasi pekerjaan yang kompleks didukung teknologi elektronik dan informasi. Hingga kini revolusi industri 4.0 ditandai dengan kemampuan teknologi sensor, keterhubungan (interconnectivity) dan analisis data yang memungkinkan kustomisasi (customization) secara massal, integrasi rantai pasokan dan efisiensi yang lebih tinggi berbasis sistem cyber-physical. Revolusi Industri 4.0 merupakan transformasi cepat dalam desain, manufaktur, operasi, sentra layanan produk dan sistem produksi[3].

Terkait dengan hal ini, Indonesia berencana membangun instalasi PLTN yangdidasarkan pada pertimbangan bahwa: (i) sumber energi fosil yang digunakan sebagai energi utama untuk pembangkitan listrik di Indonesia mulai habis, (ii) adanya tuntutan pemenuhan kebutuhan listrik menggunakan sumber energi yang bersih agarkualitas lingkungan juga bersih sesuai persyaratan pembangkit listrik di era industri 4.0. Konsekuensinya adalah upaya penggunaan sumber energi lain termasuk penggunaan sumber energi baru terbarukan (EBT) untuk menutupi kekurangan energi yang meliputi energi matahari, angin, panas bumi, air, biodiesel dan tenaga nuklir $[4,5]$.

Sesuai amanah UU No 10 Tahun 1997 tentang ketenaganukliran bahwa setiap pemanfaatan tenaga nuklir dalam hal ini pembangunan dan pengoperasian reaktor nuklir maupun instalasi nuklir, serta dekomisioning reaktor nuklir harus memiliki izin yang syarat-syaratnya diatur dalam Peraturan Pemerintah No. 43 tahun 2006 tentang perizinan reaktor nuklir (ps. 17) [6, 7]. Berdasarkan hal tersebut diperlukan kajian indeks keberlanjutan dari dimensi peraturan dalam rangka rencana pembangunan pembangkit listrik tenaga nuklir (PLTN) di Indonesia untuk mendukung revolusi industri 4.0. Dalam rangka rencana pembangunan PLTN pertama di Indonesia, dan seiring dengan era revolusi industri 4.0 telah dilakukan kajian terhadap indeks keberlanjutan dimensi peraturan pada rencana pembangunan PLTN menggunakan metode MDS.

Tujuan penelitian adalah memperoleh nilai indeks keberlanjutan dimensi peraturan yang akan digunakan sebagai masukan dalam penyusunan RPJP di Indonesia. Revolusi industri adalah perubahan radikal dan cepat terhadap perkembangan aktivitas manusia dalam menciptakan peralatan kerja untuk meningkatkan hasil industri atau produksi. Beberapa kemajuan dalam teknologi nuklir telah diimplementasikan di tingkat dunia, dan revolusi Industri 4.0 ini diharapkan dapat memberikan dampak yang signifikan terhadap kemajuan bangsa.

Dalam administrasi negara dan pemerintahan terdapat fungsi-fungsi pemerintahan untuk mengukur keberhasilan kinerja pemerintah, dan salah satu fungsi tersebut adalah "metode" atau cara, yang dalam hal ini untuk mengukur keberlanjutan dimensi peraturan dalam 
perencanaan pembangunan PLTN, yaitu $b=$ slope

$\operatorname{MDS}[8,9,10]$. $\quad$ C = error

Dalam MDS, dua titik atau obyek yang sama dipetakan dalam satu titik yang saling berdekatan.

\section{TEORI}

Untuk menghitung indeks keberlanjutan digunakan metode MDS, analisis leverage, dan analisis montecarlo.

\subsection{MDS (Multi Dimensional Scaling)}

MDS adalah perceptual mapping (pemetaan persepsi) yang mengandalkan Euclidian Distance antara satu dimensi dengan dimensi lain. Dalam $M D S$ atribut atau ukuran yang akan diukur dapat dipetakan dalam jarak Euclidian dimana benda yang dipersepsikan memiliki karakteristik yang sama dianggap memiliki jarak Euclidian terdekat. Sebaliknya obyek dengan karakteristik yang berbeda disebut memiliki dissimilarities sehingga perbedaan keduanya dapat diukur dalam jarak persepsi yang diterjemahkan dalam indekspersepsi seperti indeks keberlanjutan. Teknik penentuan jarak didasarkan pada Euclidian Distance dengan formula sebagai berikut[9,10].

$d_{1,2}=\sqrt{\left(X_{1}-X_{2}\right)^{2}+\left(Y_{1}-Y_{2}\right)^{2}+\left(Z_{1}-Z_{2}\right)^{2}+\ldots}$

Keterangan :

$\mathrm{d}_{1,2}=$ Jarak euclidian

$\mathrm{X}, \mathrm{Y}, \mathrm{Z}=$ Atribut

$1,2=$ Pengamatan

Jarak euclidian antara dua titik tersebut $\left(\mathrm{d}_{1,2}\right)$ kemudian di dalam MDS diproyeksikan ke dalam jarak euclidian dua dimensi $\left(\dot{\mathrm{D}}_{1,2}\right)$ berdasarkan rumus regresi pada persamaan berikut:

$\mathrm{D}_{1,2}=\mathrm{a}+\mathrm{b} \mathrm{D}_{1,2}+\mathrm{c}$

Keterangan :

a $\quad=$ intercept Teknik yang digunakan adalah algoritma $A L S C A L$ dan mudah tersedia pada hampir di setiap software statistik (SPSS dan SAS). Rap-Nuclear pada prinsipnya membuat iterasi proses regresi tersebut sedemikian sehingga didapatkan nilai e yang terkecil dan berusaha memaksa agar intercept pada persamaan tersebut sama dengan $0(a=0)$. Kesesuaian MDS dikaji dengan ukuran nilai STRESS.

Nilai STRESS (Standarized Residual Sum of Square) adalah ukuran ketidak kesesuaian (a lack of fit measure), makin tinggi nilai STRESS, makin nilai indeks keberlanjutan makin tidak sesuai[16]. Nilai STRESS yang rendah mengindikasikan kesesuaian yang baik. Fungsi atau nilai STRESS ditunjukkan pada Tabel 1.

Tabel 1. Nilai kesesuaian fungsi STRESS[11]

\begin{tabular}{cc}
\hline STRESS $(\%)$ & Kesesuaian (Goodness of fit) \\
\hline$>20$ & Buruk \\
$10-20$ & Cukup Baik \\
$5,1-10$ & Baik \\
$2,5-5$ & Sangat Baik \\
$<2,5$ & Sempurna \\
\hline
\end{tabular}

STRESS dapat dirumuskan dalam persamaan sebagai berikut:

stress $=\sqrt{\frac{1}{m} \sum_{k=1}^{m}\left(\frac{\sum_{i} \sum_{j}\left(D_{i j k}^{2}-d_{i j k}^{2}\right)^{2}}{\sum_{i} \sum_{j} d_{i j k}^{2}}\right)}$

Posisi titik keberlanjutan dapat divisualisasikan melalui sumbu horizontal dan vertikal dengan nilai indeks keberlanjutan yang diberi skor 0 persen (buruk) dan $100 \%$ (baik). Jika sistem yang dikaji mempunyai nilai indeks keberlanjutan lebih besar atau sama dengan 50 \%, maka sistem dikatakan berkelanjutan (sustainable), dan jika nilai indeks 
kurang dari $50 \%$, maka tidak berkelanjutan [10]. Kesalahan dalam pembuatan skor dimensi peraturan, kesalahan pemahaman terhadap atribut peraturan, dapat menyebabkan pengaruh galat dan tingginya nilai STRESS (buruk).

\subsection{Analisis Leverage}

Analisis Leverage digunakan untuk mengetahui efek stabilitas jika salah satu atribut dihilangkan saat dilakukan ordinasi. Hasil analisis Leverage menunjukkan persen perubahan root mean square (RMS) dari masing-masing atribut. Atribut yang memiliki persentase tertinggi merupakan atribut paling sensitif terhadap keberlanjutan[12].

\subsection{Analisis Monte Carlo}

Analisis Monte Carlo dimaksudkan untuk mengevaluasi pengaruh galat pada pendugaan nilai ordinasi menggunakan metode simulasi statistik untuk mengevaluasi efek dari random error pada proses pendugaan, serta nilai yang sebenarnya.

\section{METODOLOGI}

\subsection{Pengumpulan Data}

Kegiatan penelitian meliputi studi pustaka, pengumpulan data primer (pendapat para di Kementerian, Dinas Lingkungan Hidup dan Kehutanan propinsi maupun daerah, akademisi, swasta dan lainnya), dan pengumpulan data sekunder. Selanjutnya dilakukan identifikasi dan inventarisasi data, serta analisis dan evaluasi datauntuk menyusun atribut-atribut peraturan. Analisis atribut-atribut peraturan menggunakan MDS, analisis leverage dan Monte Carlo untuk menghitung indeks keberlanjutan dan peraturanperaturan yang menjadi leverage $[9,10]$.

\subsection{Pengolahan Data}

Penilaian status keberlanjutan dari dimensi peraturan menggunakan metode Rap Nuclear termodifikasi dari program Rapfish dengan teknik MDS [10,13,14,15]. Metode MDS digunakan untuk merancang model, menganalisis, serta merancang pengelolaan operasional secara berkelanjutan[14]. RapNuclear merupakan teknik statistik dengan pendekatan MDS, memberikan hasil yang stabil dibandingkan dengan metode multivariate analysis yang lain[11].

Berdasarkan Prosedur penggunaan Rapnuclear yang merupakan modifikasi dari program Rapfish, tahapan yang harus dilakukan meliputi: (i) reviewatribut dan skoring; (ii) identifikasi dan pendefinisian atribut; (iii) skoring untuk mengkonstruksi reference point untuk good dan bad; (iv) Multi Dimensional Ordination untuk setiap atribut; (v) Analisis Leverage; (vi) Simulasi Monte Carlo, (vii) analisis keberlanjutan[10]. Tahapan 1 s/d 3 disebut Rapscore dan tahapan 4 disebut Rapanalysis.

\section{HASIL DAN PEMBAHASAN}

\subsection{Review Atribut}

Pada tahapan review atribut ditemukan sebanyak 16 peraturan yang disertakan untuk membangun sistem keberlanjutan dimensi peraturan, dan ke 16 atribut peraturan tersebut ditunjukkan pada Tabel 2. Pada tabel tersebut terlihat bahwa dari ke 16 atribut peraturan terdapat 5 Peraturan Perundang-undangan, 6 Peraturan Pemerintah, 1 Peraturan Presiden Republik Indonesia, 1 Keputusan Presiden dan 3 Peraturan Kepala Badan Pengawas Tenaga Nuklir. Ke 16 
peraturan tersebut diterbitkan mulai tahun 1997 dan terus dilakukan updating dan revisi hingga sekarang menyesuaikan kondisi yang terbaru.

Tabel 2. Daftar Atribut untuk Perhitungan Indeks Keberlanjutan Dimensi Peraturan

\begin{tabular}{|c|c|c|}
\hline No. & Nama Peraturan & Tentang \\
\hline \multirow[t]{5}{*}{1} & Undang Undang Republik & Pengesahan Treaty On The \\
\hline & Indonesia No. 9 Tahun & Southeast Asia Nuclear \\
\hline & 1997 & Weapon Free Zone (Traktat \\
\hline & & Kawasan Bebas Senjata \\
\hline & & Nuklir Di Asia Tenggara) \\
\hline \multirow[t]{3}{*}{2} & Undang Undang Republik & Ketenaganukliran \\
\hline & IndonesiaNo.10 Tahun & \\
\hline & 1997 & \\
\hline \multirow[t]{3}{*}{3} & UndangUndang Republik & Energi \\
\hline & Indonesia No. 30 Tahun & \\
\hline & 2007 & \\
\hline \multirow[t]{3}{*}{4} & UndangUndang Republik & Pelarangan Uji Coba Nuklir \\
\hline & IndonesiaNo.1 Tahun & \\
\hline & 2012 & \\
\hline \multirow[t]{7}{*}{5} & UndangUndang No.10 & Pengesahan International \\
\hline & Tahun 2014 & Convention For The \\
\hline & & Suppression Of Acts Of \\
\hline & & Nuclear Terrorism \\
\hline & & Konvensi Internasional \\
\hline & & Penanggulangan Tindakan \\
\hline & & Terorisme Nuklir) \\
\hline \multirow[t]{2}{*}{6} & Peraturan Pemerintah & Perizinan Reaktor Nuklir \\
\hline & No. 43 Tahun 2006 & \\
\hline \multirow[t]{3}{*}{7} & Peraturan Pemerintah & Perizinan Pemanfaatan \\
\hline & No. 29 Tahun 2008 & Sumber Radiasi Pengion \\
\hline & & Dan Bahan Nuklir \\
\hline \multirow[t]{2}{*}{8} & Peraturan Pemerintah & Batas Pertanggungjawaban \\
\hline & No.46 Tahun 2009 & Kerugian Nuklir \\
\hline \multirow[t]{2}{*}{9} & Peraturan Pemerintah & Pengelolaan Limbah \\
\hline & No.61 Tahun 2013 & Radioaktif \\
\hline \multirow[t]{3}{*}{10} & Peraturan Pemerintah & Perizinan Instalasi Nuklir \\
\hline & No. 2 Tahun 2014 & Dan Pemanfaatan Bahan \\
\hline & & Nuklir \\
\hline \multirow[t]{3}{*}{11} & Peraturan Pemerintah & Kebijakan Energi Nasional \\
\hline & Republik Indonesia No.79 & \\
\hline & Tahun 2014 & \\
\hline \multirow[t]{3}{*}{12} & Peraturan Presiden & Pertanggungjawaban \\
\hline & Republik Indonesia No.74 & Kerugian Nuklir \\
\hline & Tahun 2012 & \\
\hline \multirow[t]{2}{*}{13} & Keputusan Presiden & Pengesahan Convention On \\
\hline & No.106 Tahun 2001 & Nuclear Safety (Konvensi \\
\hline
\end{tabular}

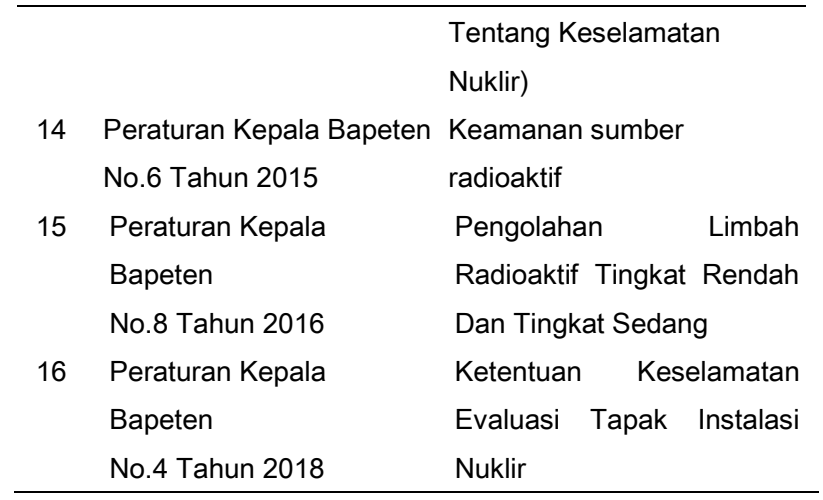

\subsection{RapScores dan RapAnalysis}

RapScores dan RapAnalysis datadimaksudkan untuk memvalidasi hasil simulasi dari RapNuclear, dan hasil menunjukkan bahwa indeks keberlanjutan dimensi peraturan sebesar 42,89.Besar indeks keberlanjutan dikelompokkan dalam 4 (empat) kategori, yaitu 0-25 (buruk atau tidak berkelanjutan), 25,01-50 (kurang berkelanjutan), 50,01-75 (cukup berkelanjutan), 75,01-100 (baik atau sangat berkelanjutan)[10]. Berdasarkan hasil perhitungan indeks keberlanjutan dari dimensi peraturan nilai tersebut $(42,89)$ dikategorikan kurang berkelanjutan karena berada pada kisaran 25-50 (Gambar 1).

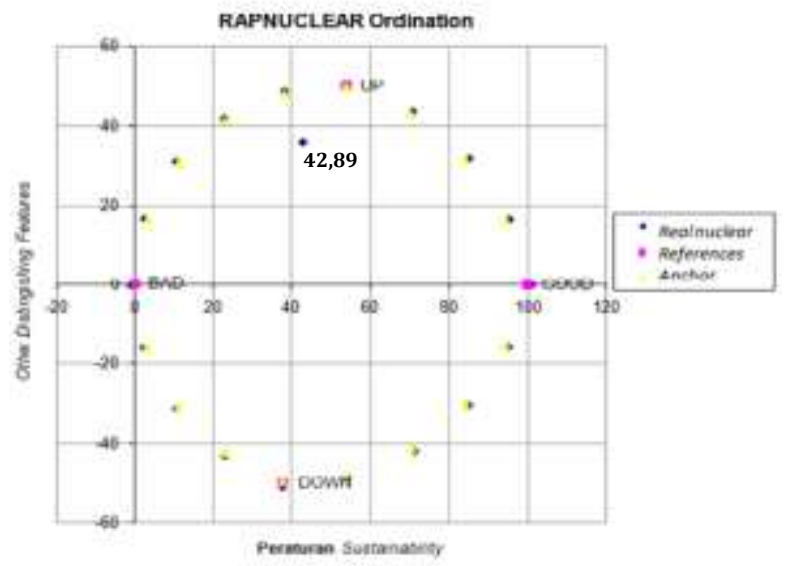

Gambar 1. Ordinasi Keberlanjutan Dimensi Peraturan.

Hal ini juga didukung dengan daya penjelas atau koefisien determinasi $\left(R^{2}\right)$ yang memiliki nilai cukup tinggi, yaitu 0,95 yang berarti bahwa ke 16 (enam belas) peraturan yang disertakan tersebut memiliki peran yang cukup besar dalam menjelaskan 
keragaman dari perencanaan pembangunan PLTN yang dibangun (created). Demikian juga didukung oleh besaran nilai STRESS 0,1331 (13,31\%), yang berarti ketepatan konfigurasi (goodness of fit) model yang dibangun untuk keberlanjutan dapat merepresentasikan model cukup baik[10,15].

\subsection{Analisis Leverage}

Berdasarkan hasil analisis leverage ditemukan dua peraturan, yaitu Peraturan Pemerintah Republik Indonesia No. 61 tahun 2013 tentang pengelolaan limbah radioaktif mempunyai bilangan RMS 6,43 dan Keputusan Presiden No. 106 tahun 2001 tentang Pengesahan konvensi Keselamatan Nuklir mempunyai bilangan RMS 6,18 sehingga kedua peraturan tersebut berpengaruh besar terhadap ketidakberlanjutan dimensi peraturan.

Peraturan Pemerintah Republik Indonesia No. 61 tahun 2013 tentang pengelolaan limbah radioaktif menjadi perhatian utama saat ini, mengingat belum semua Perda provinsi maupun daerah tentang pengelolaan limbah B3 (bahan berbahaya, beracun) telah mengatur dan mengarahkan jenis limbah radioaktif (nuklir). Sebagai contoh Perda Kabupaten Jepara No. 19 Tahun 2013 tentang Perlindungan dan Pengelolaan Lingkungan Hidup yang belum mengatur limbah PLTU (fly dan bottom ash), yang sudah jelas memberikan kontribusi limbah radioaktif (Ra-228, Ra-226, dan lainnya) ke lingkungannya. Seperti diketahui flydan bottom ash merupakan abu hasil pembakaran bahan bakar batubara (PLTU) yang mengandung sejumlah polutan radioaktif dan berpotensi membahayakan kesehatan[16]. Demikian pula Perda Kabupaten Semarang No. 26 Tahun 2016 tentang pengelolaan limbah B3, dan Perda Provinsi Kalbar No.3 Tahun 2014 tentang Perlindungan dan Pengelolaan Lingkungan Hidup yang juga belum mengatur tentang baku mutu polutan unsur radioaktif (nuklir), mengingat di daerah-daerah tersebut terdapat beberapa PLTU dan ada wacana dibangun PLTN. Hal ini akan mengurangi kepercayaan publik terkait dengan safety, security and safeguards (keselamatan, keamanan, dan perlindungan) khususnya terkait pengelolaan limbah radioaktif (nuklir).

Keputusan Presiden No. 106 tahun 2001 tentang Pengesahan konvensi Keselamatan Nuklir harus ditindaklanjuti sebagai bentuk perlindungan terhadap masyarakat Indonesia khususnya. Meskipun keselamatan nuklir merupakan kepekaan nasional, namun sesuai konsistensi Indonesia sebagai salah satu peserta penandatangan konvensi tersebut berkewajiban mengkomunikasikan kepada publik tentang hal-hal yang berkaitan dengan keselamatan nuklir di Indonesia secara utuh. Salah satu kewajiban dalam konvensi tersebut adalah menetapkan standarstandar (benchmarks) keselamatan nuklir tingkat nasional yang layak diikuti oleh Pemerintah Provinsi dan Daerah[17]. Adanya peristiwa Chernobyl, Tree Miles Island dan Fukushima merupakan pukulan dan turunnya kepercayaan terhadap teknologi nuklir, namun di sisi lain hal ini membawa perubahan meningkatnya budaya keselamatan nuklir. Secara perlahan, budaya keselamatan nuklir terbangun (created) dengan sendirinya, seperti halnya terjadi di masyarakat pada negara negara yang terkena bencana nuklir.

\subsection{Analisis Monte Carlo}

Hasil analisis montecarlo menunjukkan perbedaan nilai hasil penghitungan MDS dengan Monte Carlo yang relatif kecil (0,32 atau lebih kecil dari 1). Hal ini menunjukkan bahwa tingkat presisi keberlanjutan tinggi (baik)[10], Hasil terlihat pada Gambar 2. 


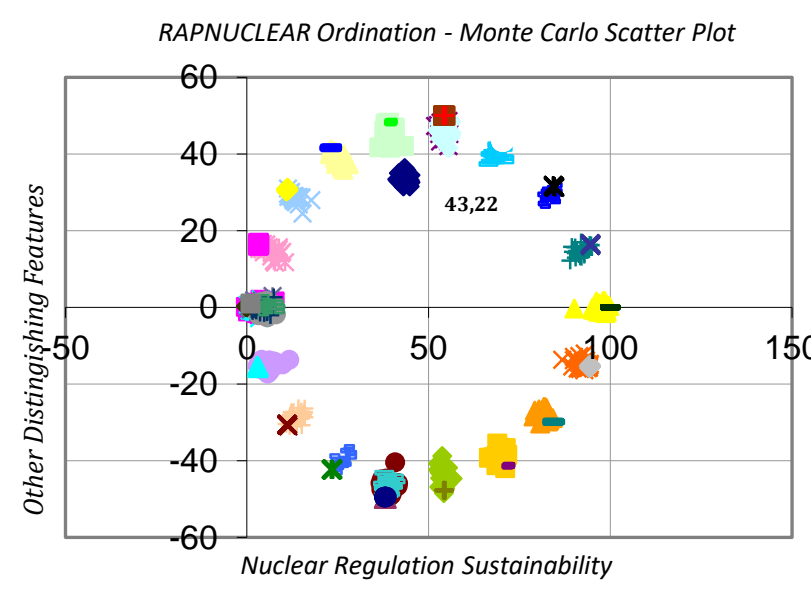

Gambar 2. Analisis Montecarlo Dimensi Peraturan.

Pada Gambar 2 terlihat bahwa nilai ordinasi keberlanjutan dimensi peraturan sebesar 43,22 sehingga selisih antara hasil ordinasi MDS $(42,89)$ dengan nilai tersebut adalah 0,33 atau dibawah 1 , artinya model keberlanjutan dimensi peraturan yang dibangun dengan menyertakan 16 peraturan mempunyai tingkat presisi tinggi.

\section{KESIMPULAN DAN SARAN}

\subsection{Kesimpulan}

Berdasarkan hasil penelitian diperoleh nilai indeks keberlanjutan dimensi peraturan sebesar 42,89, dan nilai ini bermakna kurang berkelanjutan. Agar dimensi peraturan dalam perencanaan pembangunan PLTN berkelanjutan diperlukan intervensi terhadap 2 regulasi, yaitu Peraturan Pemerintah Republik Indonesia No. 61 tahun 2013 tentang Pengelolaan Limbah Radioaktif dan Keputusan Presiden No. 106 tahun 2001 tentang Pengesahan Konfensi Keselamatan Nuklir.

\subsection{Saran}

Intervensi yang dimaksud adalah adanya langkah nyata peningkatan respon dan kapabilitas SDM berupa rumusan Indikator Kinerja Utama (IKU) dan
Indikator Kinerja Kunci (IKK) urusan LH tentang limbah B3 (termasuk limbah radioaktif/ nuklir) yang berorientasi outcome. Dengan demikian akan nampak sinergitas dan harmonisasi antara pemerintah pusat, provinsi dan daerah terkait dengan perencanaan pembangunan PLTN di Indonesia.

\section{DAFTAR ACUAN}

[1]Moendi Poernomo, 2013, "Analisis dan Evaluasi Peraturan Perundang-Undangan Tentang Ketenaganukliran", Pusat Perencanaan Pembangunan Hukum Nasional Badan Pembinaan Hukum Nasional Kementerian Hukum Dan Hak Asasi Manusia Republik Indonesia, Jakarta

[2]RISTEKDIKTI, 2018, "Penguatan Kerja Sama IndonesiaIAEA Dalam Pengembangan dan Pemanfaatan Teknologi Nuklir untuk Damai”. Ristekdikti. Jakarta, Vol 8.

[3]Reno Alamsyah. "Analisis Dampak Industri 4.0 Terhadap Sistem Pengawasan Ketenaganukliran Di Indonesia". Jurnal Forum Nuklir (JFN), Vol.12. No. 2, Hal. 47-53, 2018.

[4] Adiwardoyo. "Prospek PLTN Dalam Penyediaan Energi Nasional". Prosiding Pesentasi IImiah Daur Bahan Bakar Nuklir II, PEBN-BATAN, Jakarta, 19-20 Nopember 1996. ISSN 1410-1998, Hal. 11-18, Tahun 1996.

[5]Edwaren Liun, Sunardi. "Perbandingan Harga Energi Dari Sumber Energi Baru Terbarukan dan Fosil", Jurnal Pengembangan Energi Nuklir, Vol.16, No.2, Hal. 119-130, Tahun 2014.

[6] Menteri Negara Sekretaris Negara, 1997, Undang Undang No. 10 Tahun 1997, Ketenaganukliran, Jakarta.

[7] Menteri Hukum dan Hak Asasi Manusia, 2006, Peraturan Pemerintah No. 43 Tahun 2006 tentang Perizinan Reaktor Nuklir, Jakarta.

[8] S. Supardi,dkk. "Analisis Keberlanjutan Pembangunan Kota Tepian Pantai (Studi Kasus: Kota Baubau Provinsi Sulawesi Tenggara)". Jurnal Wilayah dan Lingkungan. Vol. 5, No. 3, Hal.188-204, 2017.

[9] M. Maharani, et.al, "Structural Model for Sustainable Management of Ruminant Catle Slaughterhouse (RC-S): The Establishement and Renovation of RC-S". Jurnal Global Veterinaria, ISSN: 1992-6197, Vol. 14, No. 5, Hal. 707-719, 2015.

[10]Kavanagh, Pand Pitcher, TJ. "Implementing Microsoft Excel Software For Rapfish: A Technique For The Rapid Appraisal of Fisheries Status. Fisheries Center Method. Rev. Vol. 12, No. 2, Hal. 136-140, Tahun 2004. 
[11] Alder J, et.al. How good is good: A Rapid Appraisal Technique For Evaluation Of The Sustainability Status of Fisheries Of The North Atlantic. Sea Around Us Method. Page 136-162, 2003.

[12]Tatan Sukwika, et.al. "Evaluating The Level of Sustainability of Privately Manage Forest in Bogor, Indonesia". Biodiversitas. Vol. 17, No.1, Page 241-248, 2016.

[13]Fauzi. A dan S. Anna. Pemodelan Sumberdaya Perikanan dan Kelautan untuk Analisis Kebijakan. PT. Gramedia Pustaka Utama. Jakarta. 2005.

[14]Lili Dahliani, et.al, "Palm Oil Sustainable Management Using MDS Model from Social Dimension", Proceeding 5th International Conference on Community Development in Asean, 19-21 juli 2018. Vol. 231. Pp.50-53, 2018

[15]Ahad A, et.al. Sustainability of tropical small-scale fisheries: Integrated assessment in French Guiana. Marine Policy, February 2014, Vol. 44, Pages 397-405.2014.

[16]Sunarko. "Kajian Risiko Komparatif Terhadap Pembangkitan Ustrik Batubara Dan Nuklir”, Jurnal Pengembangan Energi Nuklir, Volume 6 No. 3 \& 4, Hal. 47-64. 2004.

[17]Yaziz Hasan. "Peran Perjanjian Internasional Ketenaganukliran Pada Promosi Penggunaan Nuklir Tujuan Damai". Suplemen kegiatan pengenalan Perjanjian Internasional Ketenaganukliran, Jakarta, 30 April 2009 